\title{
Study on the Status Quo and Problems of Pension Institutions in Zhengzhou As Well As Countermeasures
}

\author{
- Investigation Based on 28 Pension Institutions in Zhengzhou
}

\author{
Xing Wenhui* \\ Henan Institute of Education \\ Social Demography College \\ Zhengzhou, China \\ e-mail:xingwenhui429@126.com \\ Chang Huiping \\ Henan Institute of Education \\ Social Demography College \\ Zhengzhou, China \\ e-mail: shengwuchp@126.com
}

\author{
Fu Ruimin \\ Henan Institute of Education \\ Social Demography College \\ Zhengzhou, China \\ e-mail: angelaminmin@163.com \\ Tang Wei \\ Henan Institute of Education \\ Social Demography College \\ Zhengzhou, China \\ e-mail: 25591759@qq.com
}

\begin{abstract}
With the change of aged population's structure as well as people's viewpoint on public pension, the traditional family nursing mode cannot adapt to social changes any more. Thus nursing institutions for the aged have been vigorously developed. In this paper, nursing institutions for the aged in Zhengzhou have been taken as examples to analyze the current development situation as well as existing problems with proposal of corresponding countermeasures so as to provide references for the future development of public pension institutions.
\end{abstract}

Keywords- City of Zhengzhou; Pension Institutions; Population Aging; Degree of Satisfaction; Countermeasures

\section{INTRODUCTION}

China has entered a society of aging population since 1999 with increasingly prominent problem of aging population. According to statistics, in 2004, the aged population over 60 years old accounted for $15.5 \%$ of the total population, within which the aged population over 65 years old accounted for $10.1 \%{ }^{[1]}$. It is no doubt that the increasingly serious aging population will bring severe problems to public pensions. Under such circumstance, it has been a major issue of people's livelihood needing to be solved urgently to deal with aging population actively by accelerating the development of social nursing causes for aged and exploring effective means to solve public pension issues ${ }^{[2]}$. Zhengzhou, capital of Henan which is a province with large population, had 816 thousand people over 65 years old according to the sample survey of population and urbanization issued by Statistical Bureau, accounting for $8.71 \%$ of the total population of Zhengzhou, which is far beyond $7 \%$, the international standard for aging.

At present, most studies have been carried out on pension institutions in large cities or empty-nest elders in rural areas while there have been fewer studies on central areas ${ }^{[3-6]}$. Therefore, by field study, the author has conducted deep study on the living conditions and existing problems in pension institutions in Zhengzhou with proposal of countermeasures so as to improve the quality of service and provide references for the development of public pensions, which can make the social service system more rational and perfect.

\section{RESEARCH METHODS}

In the study, questionnaire method, deep interview and documentary method are adopted by choosing 28 pension institutions in five districts like Zhongyuan District and Jinshui District as research objects. In total 312 pieces of questionnaire papers are given out with a $100 \%$ recycling of 312 , within which 302 are effective. The contents of the questionnaire referred to the elders' basic conditions, infrastructures in pension institutions, service items, elder people's spiritual need as well as their satisfaction degree and so on. Besides, deep interview is made to better know about the elders' conditions.

The results from the questionnaire are input by WPS with descriptive analysis by statistical software. Besides, factors affecting the elders' satisfaction are tested X2 so as to meet the difference of $\mathrm{P}<0.05$ with statistical significance.

\section{CURRENT SITUATION OF PUBLIC PENSION INSTITUTIONS IN ZHENGZHOU}

28 public pension institutions have been investigated in which 4 have their own hospitals and 24 are related to hospitals nearly to different degree, so they can guarantee timely treatment for elders basically. However, diversified activity places are only supplied in those of large scale.

As for the geographical distribution, 12 nursing institutions are set in the sub-urban areas, 14 are in the urban communities and 2 are in the commercial zones. As for their circumstance, most of them are close to gardens 
with the concept of keeping quiet in a noisy environment. Besides, the inside layouts are also different from each other, for example, they have single rooms, double rooms and triple rooms. But some rooms are decorated really simple with only bed and night table, while some others are really complete with television, wardrobe, bathroom and even sitting room. In general, the living environment is quiet for elders' living, but infrastructures for fitting and amusement are in shortage.

\section{LIVING CONDITIONS OF ELDERS IN PENSION INSTITUTIONS}

\section{A. Reasons for their living and their own wills}

According to the questionnaire, mainly the elders choose to live in nursing homes for three reasons, which are relief of their children's burdens, physical need and lack of partners (Fig. 1).

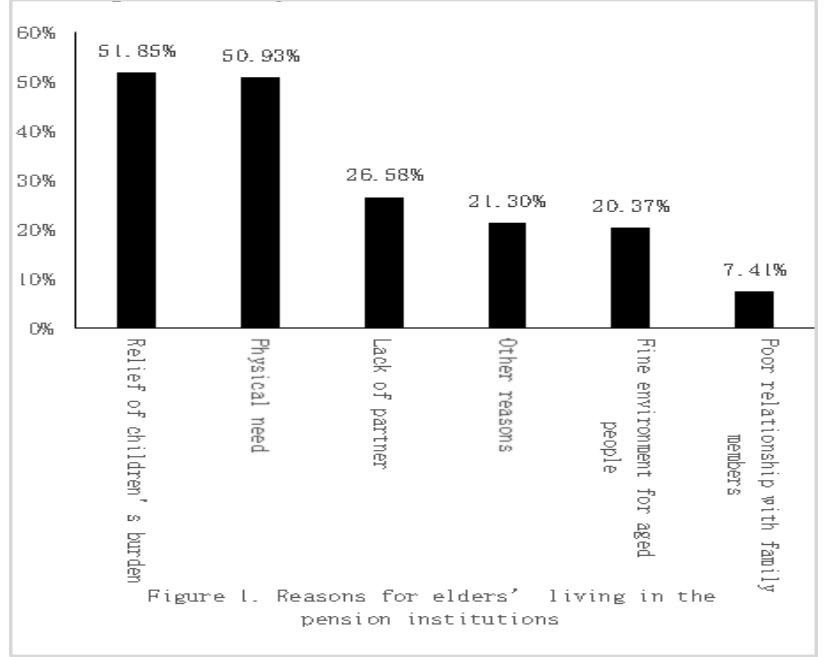

Through deep interview, it is found that most elders choose to live in nursing homes out of consideration for their children since they don't want to affect their jobs or family. With the development of society and change of family structure, young generation are faced with great pressure from work and life without much time or energy to take care of parents, and thus the elders have to live in the nursing homes for aged. The survey shows that during the interviewees, elders over 80 years account for $56.48 \%$, and those between 70 to 79 years account for $31.48 \%$. That is to say, most people living in the pension institutions are very old who cannot care themselves very well and may have accidents when they stay home alone; besides, it is inconvenient for elders who live upstairs in the city. The public pension institutions can solve these problems well. Thus, physical need is another reason for their living in nursing homes for aged.

Another reason for their living in the pension institutions is that they may feel lonely for the loss of partner. During the interview, almost $77.78 \%$ elders have lost their partners. They have no one to talk with at home, but they can look after each other and communicate with each other to relieve their lonely feelings here in nursing homes.

Above all, some elders choose to live in nursing homes only for the quiet environment since they want to avoid conflicts with children, and it is also good for both elders and children.

In general, family nursing for aged is restricted by many factors, and such insufficiency is supplemented by pension institutions. That's why more and more elders choose to live in nursing institutions. With the improvement of overall nation's quality as well as change family structure, more people will change their opinion on pensions. Therefore, it will have large space for the development of public pension institutions. Most families have only one child, so it is more suitable for elders to enjoy a happy later life by seeking more social resources.

\section{B. Quality of life}

In order to know about the basic conditions of the elders' life, issues related to food, accommodation and service attitude are included in the questionnaire. According to the survey, their attitudes toward the three aspects are as follows. Proportions of dissatisfaction are $12.04 \%, 0.9 \%$ and $1.85 \%$ respectively; proportions of ordinary feeling account for $53.7 \%, 29.63 \%$ and $24.07 \%$ respectively; and the proportions of satisfaction are $34.26 \%, 69.44 \%$ and $74.07 \%$ respectively. (Fig. 2). Obviously, the elders are dissatisfied with their meals.

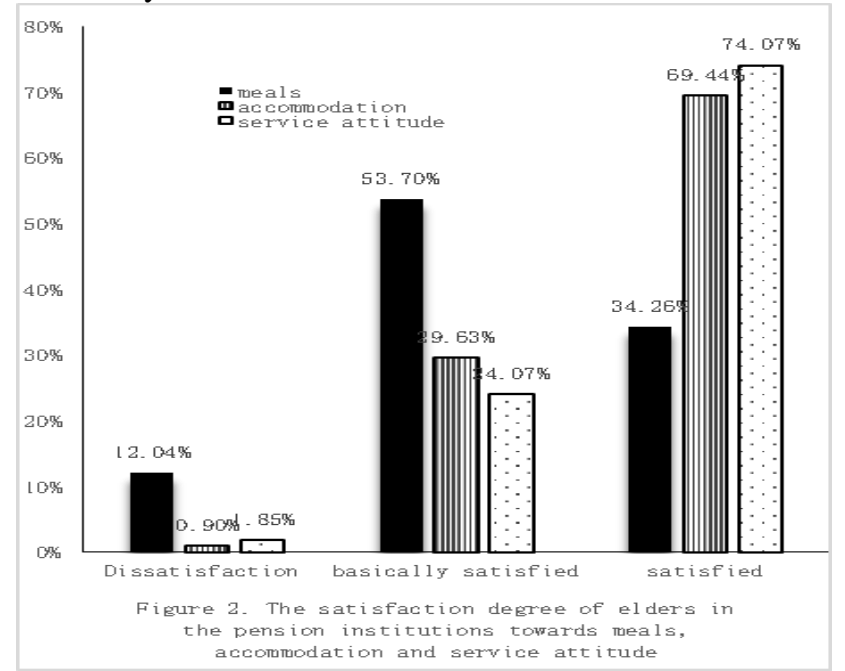

During the meal with elders, the author finds that meals in pension institutions cannot meet each one's need since some of them have trouble eating or digesting hard food like rice or braised noodles for their poor teeth. Besides, many elders reflected that though the recipe seems colorful, there is only some same food for their different names.

As for their spiritual life, the elders are asked to choose which spiritual or cultural life service shall be provided in pension institutions. $13.0 \%$ interviewees choose to hold training class and hobby class; $22.2 \%$ elders choose to organize social activities; and $41.0 \%$ elders choose to open activity room for aged specially. The rest $50.9 \%$ choose the "else" (Fig. 3). Through deep interview, the author finds that many elders have no idea about hobby class and training class without good knowledge about activity room for elders or social activities for their illiteracy and primary diploma. Most of them think it will be quite better if they can watch TV, play cards or even just bask in the sun. 


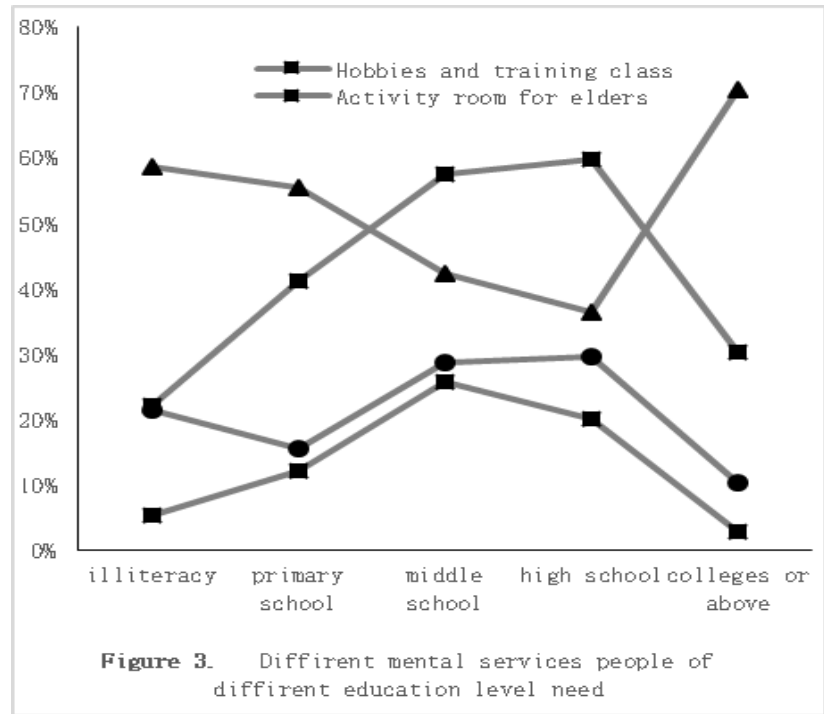

By the further analysis of the relationship between educational degree and spiritual demand for cultural service, it is found that the higher educational degree the elders have, the greater demand they have for opening social activities, hobby class and activity room; while those of middle school and high school degree have lower demand. In contrast, the trend of choosing "else" is right opposite (Fig. 3). It is rational that elders having higher degrees have more demand for spiritual and cultural demand; but why those having especially higher degree have relatively lower demand? The author gets the answer from deep interview. The reason is that elders with better education have their own interest and pursuit. They have colorful life and they can do what they interest in on they own, for example, they can write books or biography. Obviously, elders have different demands for spiritual and cultural life, so pension institutions should adjust the service contents for spiritual and cultural life according to elders' specific needs.

\section{Social relations}

In order to know about elders' social relations, I have investigated "frequency of children's visit" and "frequency of elders' participation in social activities". The result shows that the frequency of children's visit is quite different. Among those who have children, $12.9 \%$ elders' children come to see them every day; $52.5 \%$ elders' children come to see them half a month or one month; $6.9 \%$ elders' children come to see them half a year; and 5\% elders' children come to visit them once a year. Most elders said that only if their children can come to see them when they are free, they may feel satisfied, while they have no demand for the frequency.

Through deep interview, the author finds that the frequency of children's visit is related to many factors, such as the distance between their home and the nursing home as well as their work. But it has nothing to do with the number of children. It does not mean that the more children the elders have, the more time they can spend with their children.

As for social activities, $67.6 \%$ elders think it is of significance or of great significance to participate in social activities; while the actual situation is not optimistic since
$71.3 \%$ interviewees said they haven't participated in any social activities passively or voluntarily. That is to say, their practical situation is different from their will. Although they are ready to take part in social activities, they don't have enough energy. On one hand, administrators seldom organize activities for elders out of safety; on the other hand, elders themselves have poor health conditions. Therefore, most elders can only stay inside the pension institution without many opportunities to contact with the outside world or take part in social activities, though they hope to.

Besides children's visit and social activities, elders there can also keep touch with outside society by voluntary visitors. When they are asked if there are voluntary visitors there, 53.7\% elders choose "often", $39.8 \%$ elders choose "seldom", and $6.5 \%$ elders choose "never". From their opinions, it seems that over $71.3 \%$ elders hope volunteers can come frequently, while $11.1 \%$ elders hope not to be disturbed. That is, most elders hope to be concerned by the society and welcome more volunteers.

When analyzing the relationship between educational degree and expectation for voluntary visit, the author finds that elders with high-school degree or below hope volunteers can come frequently, while elders with higher degree prefer to stay alone without being disturbed. The difference is extremely obvious $(\mathrm{P}<0.01)$ (Fig. 4), indicating elders of different educational degrees have different attitudes toward voluntary visitors. The higher degree they have, the more reluctant they are to be disturbed. Actually, this is consistent with the demand analysis on spiritual life since well-educated elders have their own interest and pursuit. They things volunteers do are limited. For example, they can only accompany the elders to chat, walk and help to clean their rooms, which is of little help for elders of higher educational degree. Thus, they are more pleased to indulge themselves in their own interest and hobbies.

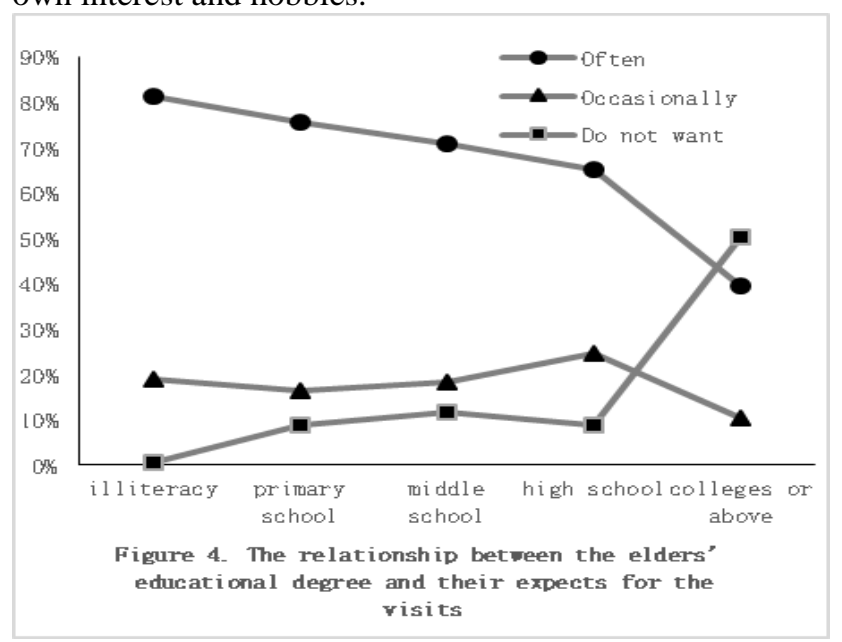

\section{Degree of satisfaction as well as the influencing} factors

When the elders are asked whether they are satisfied with the current life or not, $61.11 \%$ elders expressed they are satisfied with high satisfaction. Then, eight factors are further analyzed to explore the relations between them 
and the satisfaction, which are gender, age, degree of education, profession, frequency of children's visit, meals, accommodation and service. According to the survey result, the elders' general satisfaction is less affected by their ages, degree of education as well as frequency of their children's visit with $\mathrm{P}>0.05$; while gender, profession, meals, accommodation and service attitude have a significant effect on their satisfaction with $\mathrm{P}<0.05$ on average. For example, elders of different ages basically have the same satisfaction; however, some elders choose the "very disgusting" for meals, expressing a lowest satisfaction, and those who choose "very delicious" have a relatively higher satisfaction. Thus, these eight factors are the main factors affecting elders' accommodation ${ }^{[7-9]}$.

\section{CONCLUSIONS}

First, administrators of the pension institutions should actively seek help from national policies and social support. On one hand, they can lower the charging standard in private-funded pension institutions by national preferential policies so that more elders can afford the cost; on the other hand, the pension institutions themselves should promote their service level and transfer traditional methods of promotion with deeper influence. Thus, through these efforts, more pension institutions can be recognized by public so as to increase accommodation rate, promote benefit and further improve running condition. Then a sound circle can be formed to promote a sustainable development of pension cause.

Second, classification of functions and orientation should be clarified. Most elders living in pension institutions have poor health conditions, but they can't receive professional care from most institutions; meanwhile many demands of elders with good health can't be satisfied. Therefore, it can be learnt from the American classification standard combined with the practical situation so as to define properties and functions of different pension institutions according to different physical levels, economic levels, and geographical features and so on. By this way, more professional and characteristic service can be provided to attract different groups with better usage of self-resources.

Third, the service level should be improved and the elders' contact with outside world should be strengthened. The survey shows that elders' satisfaction can be greatly affected by the service attitude, and meanwhile the elders hope to contact with the outside frequently. According to the survey, the elders' feeling of happiness is closely related to their degree of satisfaction on living conditions, meals, medical care, recreation and fitting as well as interpersonal relations. Thus, pension institutions should improve the elders' meals, perfect recreational and fitting facilities and enrich their spiritual life. In terms of social relations, pension institutions can often organize activities together with schools, communities and charitable organizations, while the elders can choose whether to come or not according to their physical conditions and personal wills. If possible, they can also be organized to take part in outside activities to make their life happier with more significance. By this way, the goal of better pension, better medical care, better education, better learning, better acts, and better activities for elders can be realized earnestly ${ }^{[10]}$.

Fourth, the administrators' quality should be improved. Pension industry will have great potential in the future. The State Office for the aged has pointed out that in 2010 market scale of household service and nursing service has reached 130 billion, and it will exceed 500 billion in $2020^{[11]}$. The existing institutions will have greater competitive pressures. Thus, administrators should improve their own administration level as early as possible with prospective.

Fifth, professional skills of nursing staff should be promoted with better salary. On one hand, administrators should seek support from the society. The pension institutions should encourage schools to cultivate more talents in nursing aging people, or they can cooperate with schools or training institutions by implementing orderform cultivation mode. On the other hand, administrators of the pension institutions should strengthen professional concept to have class-management on nursing staff with different salaries so that nursing staff can have sound development prospect to enhance the profession and stability of the nursing team.

\section{ACKNOWLEDGMENT}

This work is supported by Key research project of Henan Province (15B180002), Basic and advanced technology research in Henan Province (152300410092).

\section{REFERENCES}

[1] Website of National Statistical Bureau of People' Republic of China.[EB/OL]. [2015-2-26].

http://www.stats.gov.cn/tjsj/zxfb/201502/t20150226_685799.html.

[2] $\mathrm{Mu}$ Guangzong.Difficulties and Countermeasures of the Development of Pension Institutions in China[J].Journal of Central China Normal University,2012,51(2):31-38.

[3] Chen Yongjie,Lu Shiyu. Challenges and Choices of Chinese Pension Service - Empirical Study on Nanhai District[M].Guangzhou: Press of Zhongshan University,2013:15-16.

[4] Zhang Guoping. Analysis on the Demand And Influential Factors of Family Pension Service in Rural Areas - Social Investigation Based on Jiangsu Province[J]. Population and Development, 2014,20 (2):95-101

[5] Zhang Wenjuan, Weimeng. Study on Elders' Will of Living in Pension Institutions in Urban Areas As Well As the Influential Factors-Taking Xicheng District of Beijing As an Example [J].Population and Economy, 2014,(6 ):22-34.

[6] Feng Zhanlian, Zhan Heying, Guan Xinping, et al. Emerging of Chinese Pension Institutions in Cities: Development and Fairness [J]. Population and Development, 2012,18 (6 ):16-23.

[7] Lidan, Xuxin, Guo Zhenyou.Investigation on Elder's Happiness and Related Factors in Nursing Homes in Tangshan[J].Modern Preventive Medicine,2013,40(19) 3633-3635.

[8] Wu Binyi, Jiqing, Huangjing. Analysis on Elders' Evaluation on Medical Service in Pension Institutions and Influential Factors.[J] Population and Development, 2014,20(3):81-95.

[9] Wang Yuhuan, Feng Yanan, Hou Weiwei. Analysis on Social Support to Elders in Pension Institutions and Influential Factors. [J].Magazine of Chinese Gerontics ,2013,33:631-634.

[10] Cheng Xiaofang, Xia Shuangyan, Xuqing. New Idea for the Construction of Social Pension System in China. [J]. Population and Development, 2014,20 (2 ):107-112. 
[11] Liu Baihui, Kou Enhui. Relations Between Social Nursing and Family Nursing under the Trend of Socialization.[J]. Population and Economy, 2015,(1):22-33. 